МУЗИКОЗНАВСТВО

УДК 781.1

\author{
Козлін Валерій Йосипович, \\ доктор мистецтвознавства, професор \\ Національної академії керівних кадрів \\ культури і мистецтв \\ ORCID 0000-0002-8974-0894 \\ Грищенко Валентина Іванівна, \\ кандидат педагогічних наук, доцент \\ Національної академії керівних кадрів \\ культури і мистецтв \\ ORCID 0000-0002-5720-0631
}

\title{
СТВОРЕННЯ МУЗИКИ У CAKEWALK SONAR PLATINUM (Частина 2)
}

Мета роботи. Музично-інформаційні технології сьогодні розвиваються дуже швидкими темпами. Дослідження присвячено висвітленню нових засобів та методів використання комп'ютерних технологій у сучасній музичній практиці на прикладі опису роботи та широких можливостей одного 3 наймогутніших музичних редакторів Cakewalk SONAR Platinum. Цей програмний продукт має можливості виконання повного циклу із запису, збереження, обробки, редагування, відтворенню цифрового саунду та зведення музики та відео. Cakewalk SONAR Platinum підходить як для домашніх студій, так і для Рroject-студій та багатоканальних комерційних систем звукозапису. Широко використовується як звукорежисерами, композиторами так i аранжувальниками. Також, методи роботи у Cakewalk SONAR Platinum можуть використовуватися для вивчення студентами, що опановують відповідні спеціальності. Методологія дослідження полягає в у виявленні та представленні практичних методів роботи у музичному редакторі на основних етапах функціонування. Наукова новизна роботи полягає в розширенні можливостей композиторів, аранжувальників, звукорежисерів і початківців музикантів при створенні музики за допомогою одного з наймогутніших сучасних музичних редакторів. Висновки. Музичний звуковий редактор CAKEWALK SONAR PLATINUM це одна 3 передових робочих цифрових аудіо-станцій, що пропонує передові технології для творчих експериментів у створенні музики.

Ключові слова: музичний звуковий редактор, озвучування, аранжування, зведення, мастеринг, композитор, звукорежисер.

Козлин Валерий Йосифович доктор искусствоведения, профессор Наџиональной академии руководящих кадров культуры и искусств; Грищенко Валентина Ивановна кандидат педагогических наук, доцент Национальной академии руководящчих кадров культуры и искусств

Создание музики в Cakewalk SONAR Platinum (часть 2)

Цель работы. Музыкально-информационные технологии в настоящее время развиваются очень быстрыми темпами. Исследование посвящено раскрытию новых способов и методов использования компьютерных технологий в современной музыкальной практике на примере описания работы и возможностей одного из самых мощных музыкальных редакторов Cakewalk SONAR Platinum, Данный программный продукт подразумевает выполнение полного цикла по записи/хранению/обработке/редактированию/воспроизведению цифрового саунда, а также сведения музыки и видео. Cakewalk SONAR Platinum подходит как для домашних студий, так и для Project-студий и многоканальных коммерческих систем звукозаписи. Широко используется как звукорежиссерами, композиторами так и аранжировщиками. Также, методы в работы Cakewalk SONAR Platinum могут использоваться для изучения студентами, которые изучают соответствующие специальности. Методология исследования заключается в определении и представлении практических методов работы в музыкальном редакторе на основных этапах функционирования. Научная новизна работы состоит в расширении возможностей композиторов, аранжировщиков, звукорежиссеров и начинающих музыкантов при создании музыки при помощи одного из самых мощных современных музыкальных редакторов. Выводы. Музыкальный звуковой редактор CAKEWALK SONAR PLATINUM это самая передовая рабочая цифровая аудио-станция, которая предлагает передовые технологии для творческих экспериментов в создании музыки.

(С) Козлін В. Й., 2019

(C) Грищенко В. І., 2019 
Ключевые слова: музыкальный редактор, озвучивание, аранжировка, сведение, мастеринг, композитор, звукорежиссер.

Kozlin Valery, Dr.Sc. In Arts, professor, of the National Academy of Managerial Staff of Culture and Arts; Grishenko Valentina, Ph.D. in Pedagogic candidate, the National Academy of Managerial Staff of Culture and Arts Creation of music in Cakewalk SONAR Platinum (part 2)

Purpose of the article. Music and information technologies are currently developing very rapidly. The study is devoted to the disclosure of new ways and methods of using computer technology in modern music practice by the example of describing the work and capabilities of one of the most powerful music editors Cakewalk SONAR Platinum, This software product involves a full cycle of recording/storage/processing/editing/playback of digital sound, as well as music and video information. Cakewalk SONAR Platinum is suitable for home studios as well as project studios and multichannel commercial recording systems. Widely used by sound engineers, composers, and arrangers. Also, the methods in the work of Cakewalk SONAR Platinum can be used for the study of students who study the relevant specialty. The methodology of the study is to identify and present practical methods of work in the music editor at the main stages of operation. The scientific novelty of the work is to empower composers, arrangers, sound engineers, and aspiring musicians to create music with the help of one of the most powerful modern music editors. Conclusions. Music sound editor CAKEWALK SONAR PLATINUM is the most advanced working digital audio workstation that offers advanced technologies for creative experimentation in creating music.

Key words: music editor, sound, arrangement, mixing, mastering, composer, sound engineer.

\section{Розділ 3. Режим запису музики в реальному часі (MIDI - Track)}

Для роботи в цьому режимі обов'язковою умовою є наявність MIDI - клавіатури або синтезатора. Ознакою MIDI треку є наявність в атрибутах символу Далі слід виділити трек. На початку роботи необхідно налаштувати звукову карту. Зробити це зручно в панелі Inspektor, aбо безпосередньо в атрибутах треку. Розглянемо цю операцію в панелі Inspektor (рис.3.1).

При відкритті вкладки 1 (клацанням на символі ) з'явиться спливаюче меню (рис. 3.2), в якому потрібно вибрати канал для треку. Нагадаємо, що в стандарті General MIDI знаходиться 15 рівноцінних каналів мелодійних інструментів та один №10 - для ударних. Природно логічно вибрати перший канал. Під вкладкою 2 знаходиться перший банк звукової карти, який вибраний автоматично. При активації вкладки 3 відкриється таблиця музичних інструментів стандарту General MIDI, в якій потрібно вибрати інструмент для даного треку. При активації вкладки 9 підключається MIDI клавіатура до відповідного входу звукової карти, або до всіх - як в нашому випадку (рис.3.3).

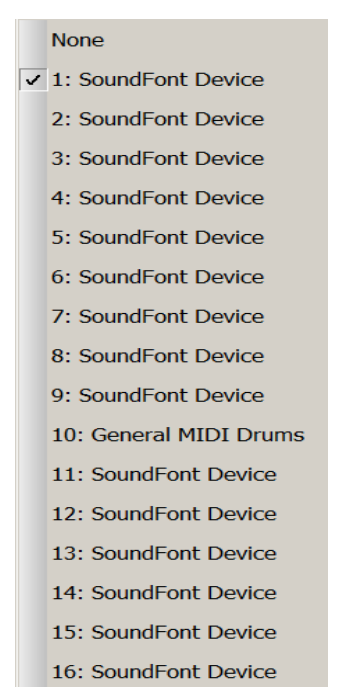

Рис.3.1. Панель Inspektor

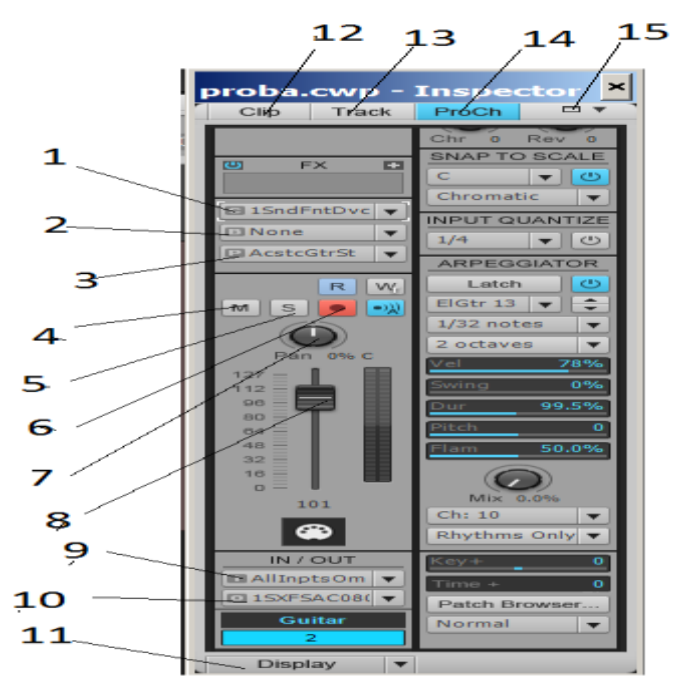

Рис.3.2. Меню вибору каналів

Активацією вкладки 10 вибираються банки звуків для даного треку, які були вибрані в програмі раніше (рис.3.4). При грі на MIDI - клавіатурі відповідно повинен з'явитися звук вибраного музичного інструменту. 


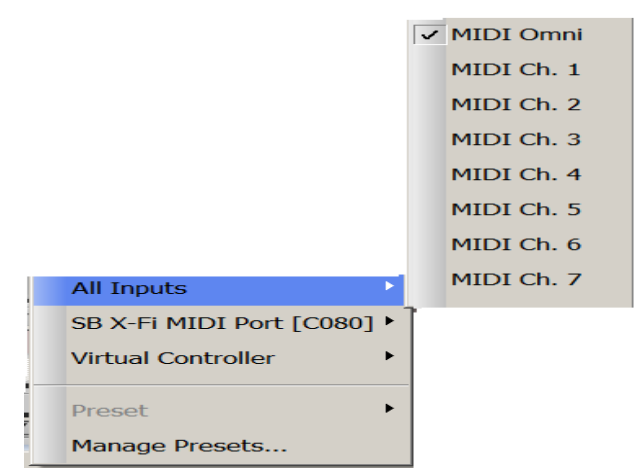

Рис.3.3. Вміст вкладки 9

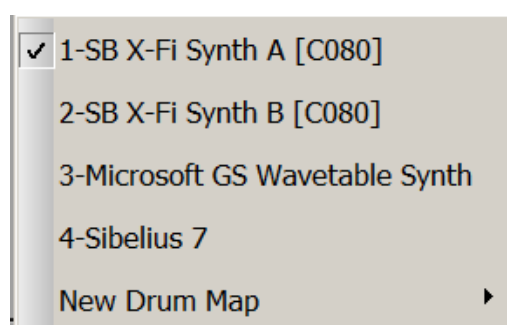

Рис.3.4. Банки звуків програми

Якщо клацнути правою кнопкою мишки по символу треку, то відкриється спливаюче меню (рис.3.5), в якому можна вибрати фотографію вибраного музичного інструменту активацією рядка Load Track Icon.

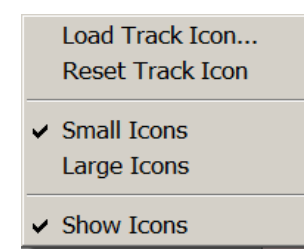

\section{Рис.3.5. Спливаюче меню вибору інструментів}

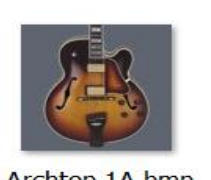

Archtop 1A.bmp

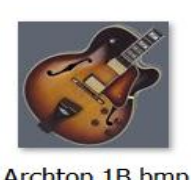

Archtop 1B.bmp

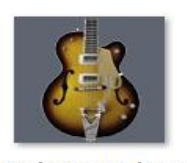

Archtop 2A.bmp

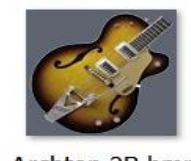

Archtop 2B.bmp

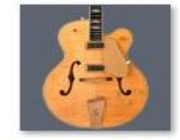

Archtop 3A.bmp

Рис.3.6. Фотографії музичних інструментів

Надалі при роботі з великою кількістю музичних інструментів, треки зручно розрізняти за виглядом інструменту. Якщо вибрати вкладку Small Icons, то зображення інструменту буде маленьким, а при Large Icons - великим.

Кнопки 4, 5 і 6 ( $M s-$ ) застосовуються відповідно для заглушення треку, включення його сольного звучання та при записі MIDI, або AUDIO інформації на трек. Ці кнопки дублюються в атрибутах треків (див.ч.1, рис.1.5). Елементи 7 і 8 служать відповідно для зміни панорами і гучності звуку треку. Елементи 4, 5, 6, 9 і 10 дублюються в секції атрибутів треку (див.ч.1, рис.1.5).

Вкладкою 11 (Display) відкривається спливаюче меню (рис. 3.7), в якому вибираються потрібні для роботи елементи інспектора.

При роботі з проектом потрібно часто звертатися до параметрів треків та кліпів. Виконати це можна за допомогою відповідних вкладок:

12 - Згортання / розвертання панелі Clip Properties Inspector;

13 - Згортання / розвертання панелі Track Properties Inspector;

14 - Згортання / розвертання панелі Pro Chanal;

15 - Згортання / розвертання панелі Inspector.

Панель Inspector може за бажанням розташовуватися в різних місцях вікна. Для цього потрібно клацнути мишкою на елементі в меню Inspector. Відкриється спливаюче меню (рис.3.8), в якому і вибирається необхідне положення панелі.

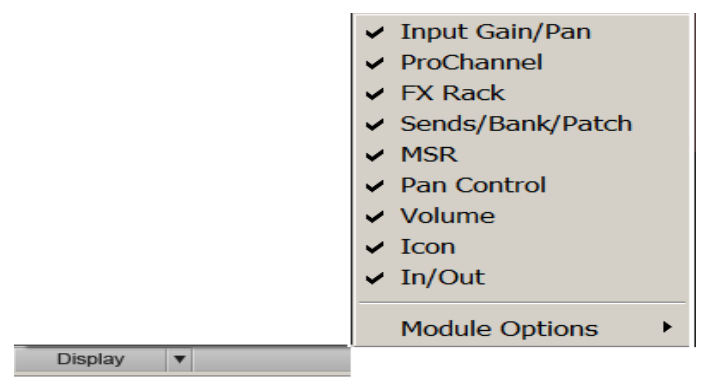

Рис.3.7. Елементи вкладки Display

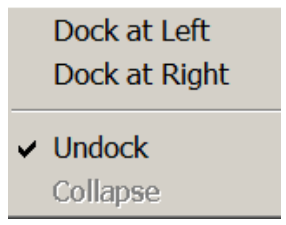

Pис.3.8. Меню панелі Inspector 
При виборі першого параметру панель буде розташована з лівого боку головного вікна, при виборі другого рядка - з правого, а при виборі третього - пї можна буде переміщувати за допомогою мишки в будь-яке місце.

3.1. Панель управління

Положення панелі у складі головного вікна показано (див.ч.1, рис.1.5).

На рис. 3.9 вона винесена окремо.

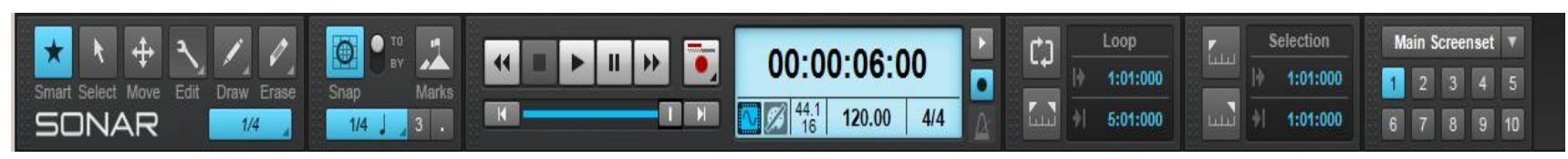

\section{Рис. 3.9. Панель управління Control Bar}

Панель управління програми SONAR містить інструменти і установки для запису, редакції і відтворення треків проекту. Панель управління складається з модулів, в кожному 3 яких міститься набір певних установок. Ці модулі можна міняти місцями, а також закривати (відкривати) в цілях звільнення простору екрану під інші потреби. Модулі розділені один від одного вертикальними темними смугами по висоті панелі (рис.3.10). Якщо кликнути правою кнопкою мишки по смузі та виділити із списку пункт Modules, то відкриється список модулів панелі управління, які можна робити видимими на ній. Призначення деяких модулів буде розглянуто у подальшому опису. Прапорці перед модулями свідчать про їх присутність на панелі, щоб прибрати модуль достатньо клацнути мишкою по прапорцю поряд його назвою.

За умовчанням панель управління закріплена у верхній частині екрану програми SONAR, але iï також можна перемістити вниз. Для цього потрібно виділити рядок Dock Control Bar at Bottom. Модуль можна розташовувати на панелі за уподобанням, якщо схопити його мишкою і перемістити вліво, або управо. Модулі можна змінювати за розміром. Для цього слід кликнути правою кнопкою мишки по необхідному модулю, активується список (рис.3.11), в якому можна вибрати необхідний розмір - відповідно Small (маленький), Medium (середній), або Large (широкий).

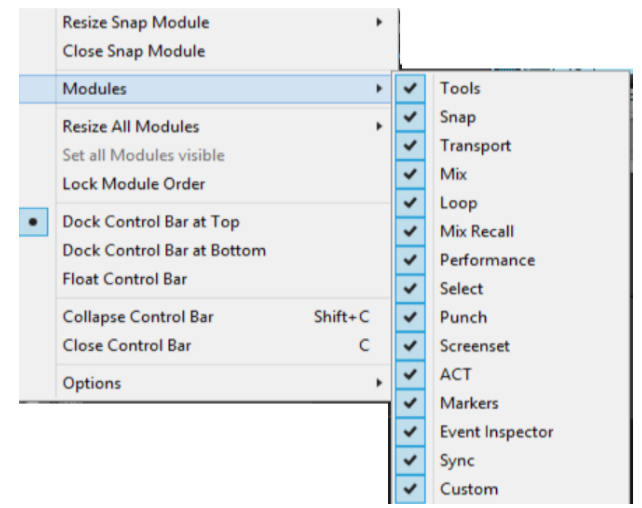

Рис.3.10. Модулі панелі управління Control Bar

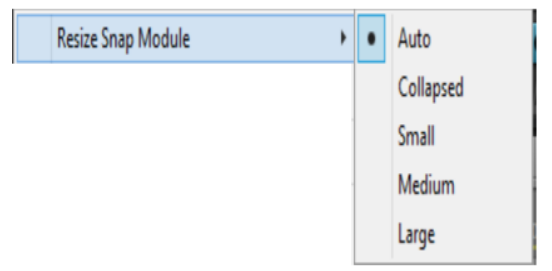

Рис.3.11. Вибір розміру модуля

\footnotetext{
3.2. Транспортна панель

При роботі у режимі запису музики в реальному часі основним модулем є транспортна панель (рис.3.12).
} 


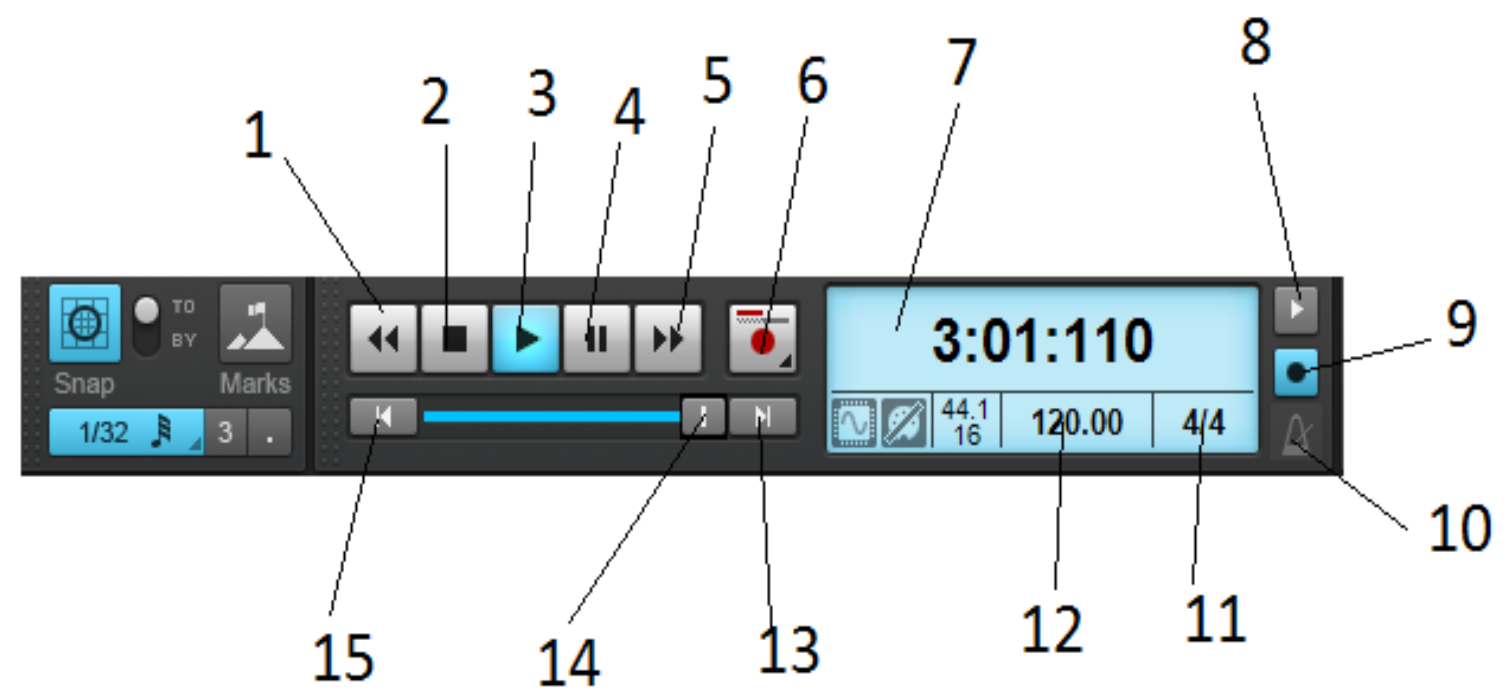

Рис.3.12. Транспортна панель

Кнопки транспортної панелі стандартні, а саме: 1- перемотування вліво, 2 - зупинка, 3 програвання (або клавіша пропуск), 4 - пауза, 5 - перемотування управо, 6 - запис, 7 - покажчик поточного положення курсору, 8 - кнопка включення (виключення) метронома при звучанні фрагменту, 9 - кнопка включення (виключення) метронома при записі фрагменту, 10 - установки метронома, 11 - зміна розміру, метра і тональності, 12 - зміна темпу, 13 - переміщення слайдеру тактів в кінець, 14 - ручне переміщення слайдеру тактів, 15 - переміщення слайдеру тактів у початок.

При клацанні правою кнопкою мишки по верхній половині покажчика - 7 відкриється вікно рис.3.13, в якому можна вибрати формат покажчика: 1- в тактах, ударах, тіках; 2 - в годиннику, хвилинах, секундах, фреймах, мілісекундах, або семплах.

\section{$M: B: T$ \\ $\mathrm{H}: \mathrm{M}: \mathrm{S}: \mathrm{F}$ \\ Millisecond \\ Samples}

\section{Рис.3.13. Вікно формату положення курсора}

Для запису інформації на трек потрібно заздалегідь налаштувати метроном. Потім виділити мишкою потрібний MIDI - трек (кликнути по його номеру), далі включити кнопку запису на треку (вона засвітиться червоним кольором) і включити кнопку запису (6) на транспортній панелі в панелі управління (рис.3.12), або використовувати гарячу клавішу R.

Запис почнеться після закінчення заданого в метрономі затакту. Зупинити його можна кнопкою зупинка (2, або Spacebar клавіатури комп'ютера. Результати запису будуть відображені у правій частині треку у вигляді рисок, по яких можна орієнтовно судити про тривалість нот та висоту їх щодо один одного (рис.3.14).

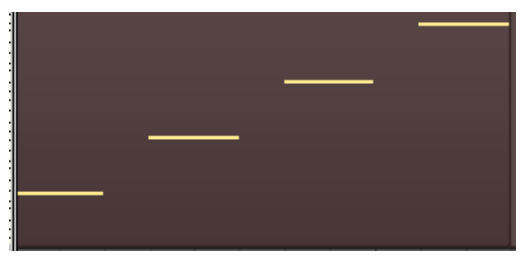

Рис.3.14. Результати запису на трек 
3.3. Модуль Tools панелі управління

Для роботи над проектом створення музики в даному режимі одним з основних елементів панелі управління $є$ модуль інструментів Tools.

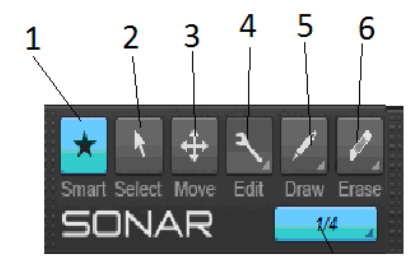

\section{Рис.3.15. Модуль інструментів}

Складові модулів: 1 - Smart - для переміщення меж записаного фрагменту, 2 - Select - для виділення зони кліпу, 3 - Move для переміщення всього кліпу, 4 - Edit - для редагування кліпу, 5 Draw Free Hand - для рисування нот, 6 - Erase - для видалення виділеного фрагменту. Представлені розшифровки складових наглядно визначають їх призначення. Разом з тим потрібні деякі пояснення.

Опція Smart зручна у тому випадку, коли потрібно розширити, або звузити розміри кліпу. Для цього потрібно виділити Smart та відпустити кнопку мишки, підвести її курсор до необхідної межі семплу. Семпл прийме вигляд двох направленої стрілки, далі натискувати на кнопку мишки i потягнути межу в потрібному напрямі наприклад, (рис.3.16).

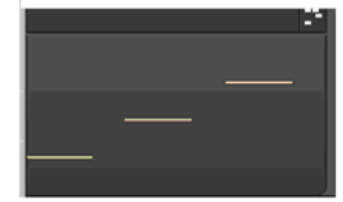

стало

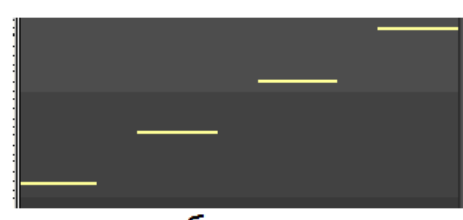

було

\section{Рис.3.16. Зміна звукового розміру кліпу}

Кнопкою 2 зручно користуватися для вирізування частини звукового фрагменту, видалення його, або копіювання, процесу зациклення тощо. Для використання кнопки 2 потрібно кликнути по ній та провести курсором мишки по лінійці часу та виділити потрібний фрагмент (рис.3.17 зліва).

Для збереження фрагменту треба скористатися клавішами Ctrl + 3, клацнути мишкою на необхідному місці лінійки часу, або треку для переміщення курсору і скористатися клавішами Ctrl + V. Результат операції на рис.3.17 справа.

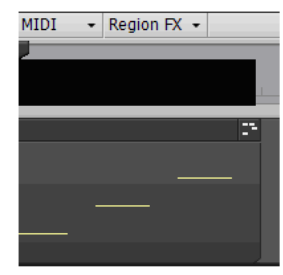

було

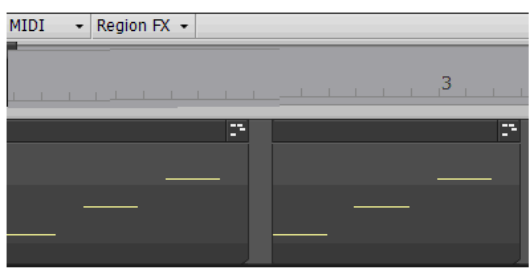

стало

\section{Рис.3.17. Копіювання фрагмента}

Для видалення фрагменту потрібно скористатися клавішею Delete комп'ютера. Найбільш точно виділити необхідний фрагмент можна за допомогою модуля виділення Selection панелі управління рис.3.18. 


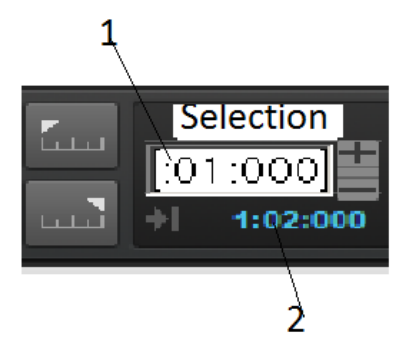

\section{Pис.3.18. Модуль Selection}

Початок зони виділення необхідно задати у верхньому списку Select From (1) в тактах, частках і тіках, а потім задати кінець зони виділення в нижньому списку Select Thru (2) та підтвердити дії кнопкою Enter комп'ютера. Виділення відобразиться на панелі часу (рис.3.17 зліва).

Можна перевести програму в режим зациклення, при якому на початку програвання циклу автоматично створюватиметься трек з новим записом. У результаті цього, можна прослуховувати кожний з варіантів та вибрати найвдаліший запис. Для виконання зациклення спочатку треба у вікні Preferences (рис.3.19) в полі Loop Recording (запис циклу) вибрати пункт (2) - Store Takes in Separate Traks (створювати окремі треки).

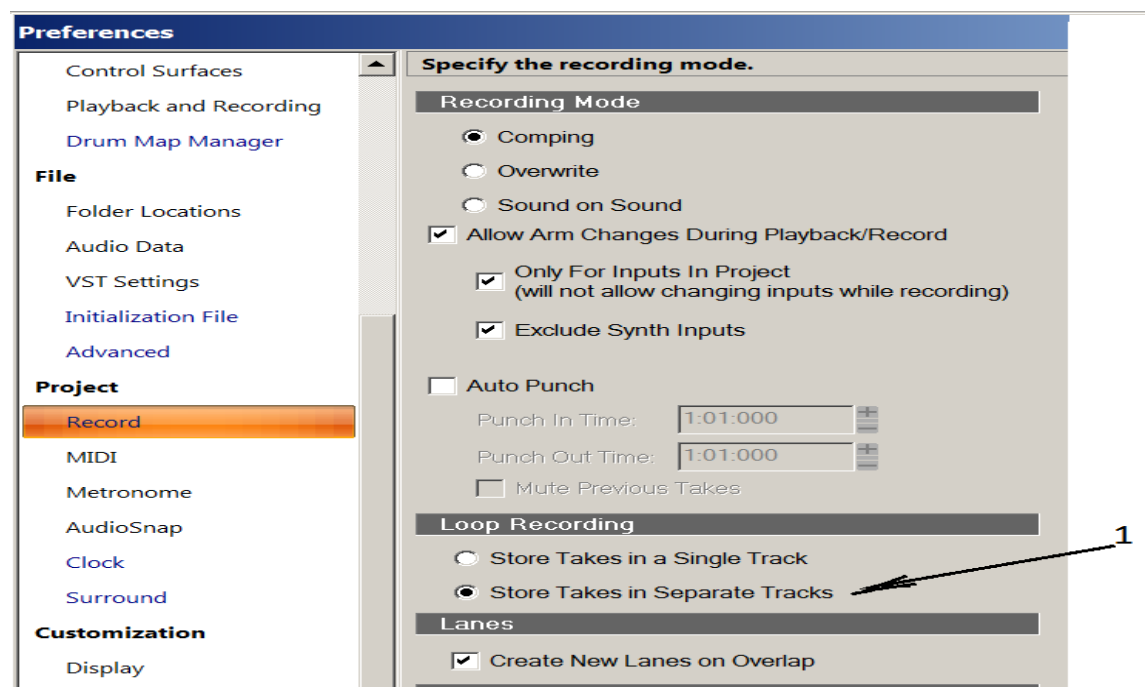

\section{Рис.3.19. Створення окремих треків}

Потім в панелі управління вибрати модуль зациклення (рис.3.20) та задати на ньому у списку 1 (початок) і 2 - (кінець) - розміри зациклення і підтвердити кнопкою Enter. Результат зациклення з'явиться на панелі часу у вигляді двох жовтих маркерів циклу, які можна перетягувати мишею в нові позиції (рис.3.21).

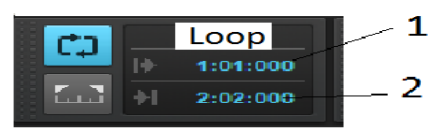

Рис.3.20. Модуль зациклення

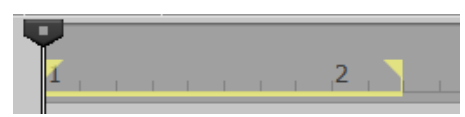

Рис.3.21. Результат зациклення

Після цього налаштування можна починати запис за допомогою MIDI - клавіатури, або синтезатору, що автоматично визначає, що працювати в режимі реального часу можуть тільки професійні музиканти - клавішники.

За допомогою кнопки Move (3) (рис. 3.15) можна копіювати кліпи на одному треку, або створювати нові. Якщо при виділеній кнопці Move, схопити кліп мишкою і перетягнути в межах треку, то з'явиться нове вікно рис.3.22, яке з'являтиметься кожного разу, поки встановлено прапорець Ask This Every Time. Опції вікна наступні:

- $\quad$ Blend Old and New - змішувати нові дані, які вставляються, з існуючими. 
- $\quad$ Replace Old with New - замінити старі дані новими. Якщо встановлений прапорець Delete Whole Measures, то незалежно від того, яку частину такту займають нові дані, старі будуть видалені зі всього такту.

- $\quad$ Slide Over Old to Make Room - вставляти переміщувані кліпи, розсовуючи існуючі дані. Якщо відзначений прапорець Align to Measures, то дані будуть вставлені в початок найближчого такту.

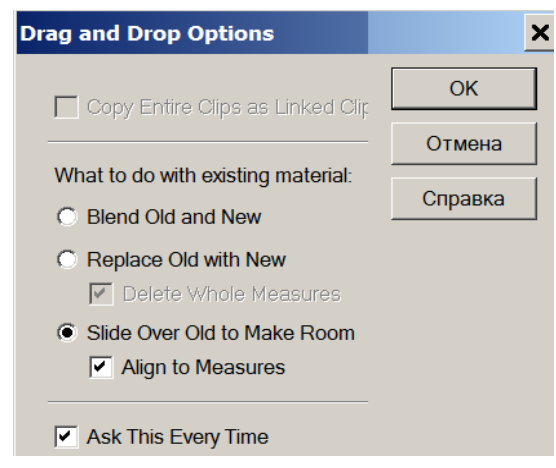

\section{Рис.3.22. Вікно копіювання кліпів}

Якщо перетягнути кліп нижче за початковий трек, то буде створено новий трек з даними, а в старому треку вони видаляться. Якщо утримувати при переміщенні кліпу кнопку Ctrl, то на новому треку з'являться початкові дані і вони збережуться на старому треку.

Кліп можна розрізати та склеювати. Для розрізання потрібно встановити курсор в потрібну позицію на лінійці часу, або в полі кліпу і клацнути правою кнопкою мишки. Відкриється список рис.3.23 і при активації рядка Split відкриється нове вікно рис.3.24.

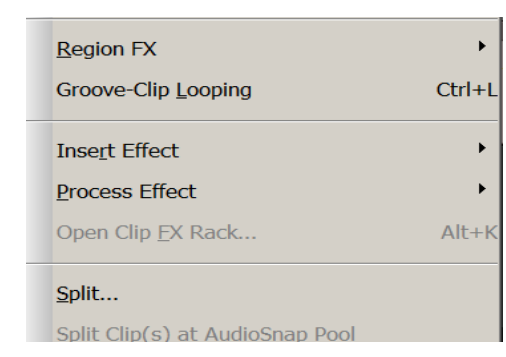

Рис.3.23. Частковий список для розрізання клiny

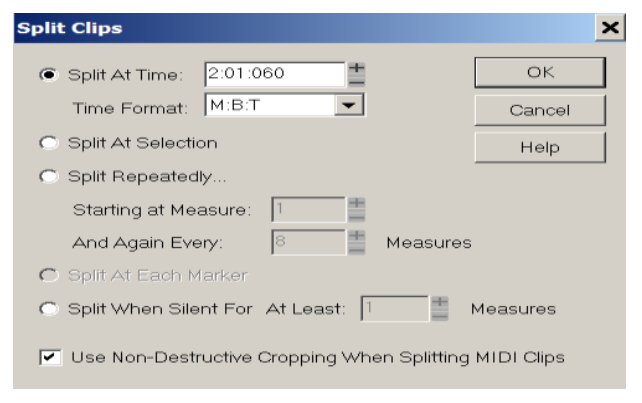

3.24. Перевірка місця розрізання кліпу

В полі Split At Time перевіряється точність установки курсору, і при необхідності вона коригується. Установки підтверджуються клавішею "ОК". Розрізані частини стають самостійними і 3 ними можна виконувати всі зазначені вище дії. Для склеювання окремих частин потрібно одну з них виділити інструментом Move Tool (рис.3.15). Далі зістикувати з іншою частиною кліпу та виділити іiі за допомогою клавіші Shift клавіатури комп'ютера. Потім кликнути правою кнопкою мишки по активованому фрагменту і в списку (рис.3.25), що з'явився, вибрати рядок Bounce to Clip(s).

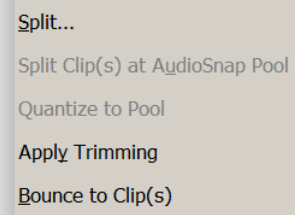

\section{Рис.3.25. Частковий список для склеювання кліпів}

Дослідження передових технології методів роботи у цифровій аудіо-станції CAKEWALK SONAR PLATINUM продовжено у частині 3. 


\section{Jimepamypa}

1. Петелин Р.Ю., Петелин Ю.В. Cakewalk SONAR 4 Producer Edition . Секреты майстерства. СПб, :БХВ.Петербург, 2005. 960 с.

2. Петелин Р.Ю. Сочинение и аранжировка музыки на компьютере. СПб.:БХВ -Петербург. 2009.608 с.

3. Программа Cakewalk SONAR. URL: https://books.google.com.ua/books?isbn=5977506287 (дата звернення 20.05.2018).

4. Программа Cakewalk SONAR. URL: https: //sonarmusic.ru/index.php/news/373-sonar-2015.html (дата звернення 26.06.2018).

5. 9 лучших DAW-программ для создания музыки на компьютере. URL: https: /lifehacker.ru/9sequencers-win-macos/ (дата звернення 26.06.2018).

\section{References}

1. Petelin R.Yu., Petelin Yu.V. Cakewalk SONAR 4 Producer Edition. Secrets of maysterstva. SPb: BHV. Petersburg 2005. 960 p. [In Russian].

Russian].

2. Petelin R.Yu. Making and arrangement of music on a computer. SPb.: BHV. SPb. 2009. 608 p. [In

3. Cakewalk SONAR program. (n.d.). Retrieved from : https://books.google.com.ua/books?isbn=5977506287 2015.html

4. Cakewalk SONAR program. (n.d.). Retrieved from : https: //sonarmusic.ru/index.php/news/373-sonar-

5. 9 best DAW programs to create music on your computer. (n.d.). Retrieved from : https: /lifehacker.ru/9sequencers-win-macos

Стаття надійшла до редакції 15.11.2018 p.

УДК 78.071.1+78.031.4 (477)

Кушнірук Ольга Панасівна, кандидат мистецтвознавства, старший науковий співробітник відділу музикознавства та етномузикології

Інституту мистецтвознавства, фольклористики та етнології ім. М. Т. Рильського НАН України

ORCID 0000-0002-0766-2555 okushniruk@yahoo.com

\section{ДЖЕРЕЛОЗНАВЧІ АСПЕКТИ ПРОБЛЕМИ «КОМПОЗИТОР І ФОЛЬКЛОР» У ТВОРЧОСТІ О. ЯКОВЧУКА}

Мета дослідження полягає у висвітленні проблеми «композитор і фольклор» у творчому доробку О. Яковчука з точки зору джерелознавчого аспекту. Методологія дослідження заснована на застосуванні культурологічного підходу, джерелознавчого, текстологічного методів. Зазначений підхід дозволяє розкрити дискурс побутування музики О. Яковчука в культурному просторі України. Наукова новизна. У статті вперше висвітлюється проблема «композитор i фольклор» у творчому доробку О.Яковчука 3 точки зору джерелознавчого аспекту. Також вперше проаналізовано дві статті самого композитора про техніку його опрацювання народних мелодій і підкреслено їх цінність для подальшого дослідження музики митця. Висновки. Одним із напрямків пізнання авторського стилю сучасного українського композитора О. Яковчука виявилася проблема «композитор і фольклор», що посідає провідну роль для розуміння національної означеності стилю майстра. Серед представленого огляду даного вектору джерел особливо цінними є дві статті (передмови до збірок) самого композитора, що уможливлюють зрозуміти логіку його музичного мислення в жанрі обробки народної пісні.

Ключові слова: українська музика, музичне джерелознавство, композитор і фольклор, обробка народної пісні, О. Яковчук.

Кушнирук Ольга Афанасьевна, кандидат искусствоведения, стариий научный сотрудник, старший научный сотрудник отдела музыковедения и этномузыкологии Института искусствоведения, фольклористики и этнологии им. М. Т. Рыльского НАН Украинь

Источниковедческие аспекты проблемы «композитор и фольклор» в творчестве А. Яковчука

Цель работы. Осветить проблему “композитор и фольклор” в творческом наследии А. Яковчука с точки зрения источниковедческого аспекта. Методология исследования основана на применении 